\title{
Huellas ideológicas en la lexicografía cubana ${ }^{1}$
}

\author{
Aurora M. Camacho Barreiro \\ Instituto de Literatura y Lingüistica. La Habana
}

Si se intentara hacer una historia de la lingüística cubana sería imprescindible dedicar un abultado capítulo a la historia de la lexicografía o elaboración de diccionarios. Para Rodolfo Alpízar:

Referirse a la lexicografía es prácticamente tratar del desarrollo de la lingüística en Cuba, pues desde sus mismos comienzos, la principal ocupación de los especialistas del país, profesionales o simples aficionados, ha sido la elaboración de inventarios léxicos o el análisis de elementos léxicos de la variante cubana del español (s. f.: 1).

Ciertamente, se tiene noticias de la motivación que ya desde el siglo $\mathrm{XVIII}^{2}$ despertaba en los hombres de letras y de ciencia la preparación de repertorios de palabras, como expresión de una herencia enciclopedista, pero que sin dudas se adentraba mucho más en la cultura de raíz grecolatina.

Los diccionarios -a diferencia de lo que muchos podrían pensar, en una aproximación epidérmica al fenómeno- no son solamente inventarios más o menos precisos, más o menos completos, más o menos útiles de palabras agrupadas según el tradicional orden alfabético y en los cuales la labor abnegada de solitarios diccionaristas o de grupos de trabajo

1 Este trabajo reúne algunos apuntes extraídos del libro en preparación acerca de las huellas identitarias e ideológicas en la lexicografía cubana hasta la década del 60 del siglo XX, proyecto que fuera ganador de la beca de creación Razón de Ser, del Centro Alejo Carpentier en el año 2000. Una versión abreviada del mismo fue presentada, asimismo, en la Conferencia Internacional Lingüística 2003, en La Habana.

2 Buena muestra de esta afirmación se encuentra en la "Memoria que promueve la edición de un Diccionario provincial de la Isla de Cuba", de Fray José María Peñalver, de 1795 , uno de los primeros documentos lingüísticos cubanos. 
se vierte de manera fría y esquemática. Un diccionario puede revelarnos, más allá de la definición misma que ofrezca, diversos aspectos de hondo significado a la hora de estudiar la historia y la cultura de una nación.

Para Luis Fernando Lara, quien ha desarrollado uno de los modelos teóricos más sólidos en lexicografía en las últimas décadas a través de su teoría del diccionario monolingüe,

El diccionario es [...] fundamentalmente un depósito de la experiencia social manifiesta en palabras, que deriva su valor de su capacidad de superar la memoria de cada uno de los individuos que componen la sociedad (1990: 30).

A través de las palabras, en efecto, el diccionario reúne los elementos de la cultura que la origina y de la cual es producto. Por esta razón, al adentrarnos en las páginas de estos repertorios de palabras podemos incluso, recrearnos frente a una especie de fotografía ampliada de una sociedad dada. Así también los diccionarios han pasado a ser de libros singulares o raros a punto de mira para la lingüística, en tanto objetos verbales.

Francisco Javier Pérez, quien ha estudiado el vínculo entre los diccionarios y la etnografía en el entorno venezolano, ha advertido que los primeros:

[...] deben considerarse como producciones culturales en la medida en que son modalidades textuales implicadas de particulares visiones del mundo y de determinados criterios de interpretación de las realidades [...] (2000: 39).

Su análisis se acerca, sobre todo, al componente etnográfico y se propone aislar los fenómenos y procedimientos de mediatización o condicionamiento ideológico y explicar sus rasgos más persistentes y notorios (2000: 41). Nuestra investigación, de alguna manera, es deudora de su interesante propuesta.

Para Manuel Seco, uno de los indicadores más claros de la robustez cultural e intelectual de una comunidad viene dado por el lugar que en ella ocupan los diccionarios (1987: 8). Si se explora en la historia de la lingüística en Cuba, se podrá comprobar que los diccionarios han sido un instrumento de profundización en nuestras raíces idiomáticas. A manera de muestra, conviene mencionar las siguientes aportaciones cuba- 
nas en esta materia: Diccionario cubano, etimológico, razonado y comprensivo de las voces y locuciones del lenguaje común y el de las dicciones del nomenclatur geográfico (1885), de José Miguel Macías; Cuba primitiva, origen, lenguas, tradiciones e historia de los indios de las Antillas Mayores y las Lucayas (1886), de Antonio Bachiller y Morales, Lexicografía antillana (1914), de Alfredo Zayas, la Enciclopedia popular cubana (1948-1949), de Luis Bustamante, entre otras que se comentarán en estas páginas.

El nivel de la palabra o nivel lexical resulta de una flexibilidad y riqueza singular y por ello, los lexicógrafos sortean todas las dificultades que este tipo de trabajo puede acarrear y en sus repertorios dan cuenta de un estado de la lengua en un momento dado.

Los diccionarios aportan información ortográfica, elementos definitorios y otros, pero sobre todo legitiman el uso de una determinada palabra en un contexto lingüístico dado. El lector común se asegura del uso real de una u otra palabra en un contexto lingüístico determinado con la consulta de un lexicón. No pocas veces se escucha decir que una palabra "no existe", porque no aparece en un diccionario y si ocurre así, entonces se trata de buscar otra aceptada ya por las autoridades en materia idiomática. El diccionario es normativo por su propia naturaleza y siempre está rezagado con respecto al uso cotidiano de la lengua, en una palabra, con respecto al habla viva de la gente.

Ahora bien, más allá de la intención de los individuos que por vocación o por oficio se encargan de elaborar diccionarios, estas obras nos revelan información de enorme significado. La propia selección del material léxico -ausencias y presencias cargadas de significación-así como la información propiamente lexicográfica vertida en las definiciones constituye un producto cultural e ideológico que reclama una mirada crítica, atenta y "maliciosa", al decir de Blecua. Se trata, en definitiva, de considerar sociológicamente el texto lexicográfico (Pérez 2000: 12) a través de un profundo y detallado estudio, entre otros componentes del artículo lexicográfico, del núcleo semántico o segundo enunciado -según la terminología de Seco-que se expresa en el acto verbal de respuesta constituido por la definición. 
Aunque los creadores de repertorios de palabras se plantean cierta asepsia y parten del principios de imparcialidad, sus producciones revelan en mayor o menor grado su espíritu, sus opiniones y juicios, y hasta sus estados de ánimo. Al alejarse de la objetividad, que es un principio fundamental de la lexicografía moderna, un hacedor de diccionarios puede "dejar entrever su personalidad, sus filias y sus fobias" (Anglada y Bargalló 1999: 960)

En opinión de Manuel Alvar Ezquerra:

Es inevitable que las obras lexicográficas reflejen las tendencias ideológicas, pues sus autores son hombres, y como tales difícilmente pueden despojarse de su propio pensamiento (1993: 185).

No debe ignorarse, entonces, el papel ético del lexicógrafo, quien puede trasladar a su creación mensajes subliminales y enunciados manipuladores, de una u otra tendencia, o postura ideológica, sea esta encubierta o transparente.

Alvar Ezquerra ha advertido también que a la hora de emprender un análisis del discurso lexicográfico se comprueba la presencia o ausencia de determinadas voces, la forma de definirlas, la selección de los ejemplos textuales, así como el empleo de las ilustraciones, elementos todos que pueden estar cargados -en mayor o menor medida- de informaciones subjetivas.

Ha sido de gran utilidad en nuestra investigación preliminar, asimismo, un estudio de Esther Forgas en el que analiza tres décadas de la sociedad española a través de los ejemplos lexicográficos aparecidos en recientes ediciones del Diccionario de la Lengua Española, de la Real Academia, y en el que sustenta que los ejemplos constituyen un entramado de personajes y conceptos arquetípicos que pueden servir, quizás mejor que cualquier compendio de moral o tratado de sociología, para definir las coordenadas culturales de una época. A esta autora y su equipo de colaboradoras de la Universidad Rovira i Virgili, así como a las profesoras $\mathrm{M}^{\mathrm{a}}$ Ángeles Calero y Rosa Mateus, de la Universidad de Lleida, debemos una serie de estudios sobre la enunciación sexista y racista, así como sobre juicios de valor en torno a temas morales y políticos subyacentes en los repertorios académicos. La marcación gramati- 
cal y las indicaciones sociolingüísticas y pragmáticas contienen asimismo - como también han demostrado ${ }^{3}$ - una alta dosis de subjetividad.

Por otra parte, en un análisis ejemplar acerca del Diccionario nacional o gran diccionario clásico de la lengua española, de Ramón Joaquín Domínguez, editado entre 1846-1847, Seco comenta el fenómeno.

Las opiniones filosóficas, religiosas, políticas, estéticas, morales del redactor, sus sentimientos, sus circunstancias personales deben desvanecerse por completo detrás del tejido verbal de sus enunciados definidores (1987: 154-164).

Unas décadas atrás, Julio Casares, un clásico de la lexicografía hispánica, hacía referencia a la necesidad de que el redactor de un diccionario empleara una prosa "esterilizada" y le recomendaba especialmente:

[...] una constante vigilancia de su pluma para cerrar el paso a toda clase de exhibiciones individuales, desde las que se reflejan en la manera personal de expresarse, en el estilo, hasta las que denotan simpatías o antipatías, tendencias políticas, credos filosóficos, religiosos, etc. (1950: 144).

No menos determinantes resultan sus planteamientos acerca de "la lengua" que debe emplear el lexicógrafo, a la que califica de artificial.

Pensamos en la lengua de la pura especulación científica, que evita cuidadosamente toda asociación secundaria y concentra su esfuerzo en ser precisa, unívoca e impersonal (1950: 143).

Estas palabras se corresponden con un "deber ser", pero la práctica lexicográfica hispánica refleja una tendencia contraria -consciente o no-, pero esencialmente diferente. La producción de diccionarios en América resulta heredera también, entre otros aspectos, de la llamada "estilística subjetiva". Cuba no podía ser una excepción.

3 Entre otros estudios, se recomienda el análisis sobre la presencia del locutor en el seno del enunciado a través de la presencia de pronombres personales y desinencias verbales, de adjetivos y pronombres demostrativos, de adjetivos posesivos, de adverbios temporales y espaciales y los llamados "subjetivemas", que se manifiestan "cuando el enunciador se erige como fuente evaluativa de sus afirmaciones" (Forgas y Herrera, 2000: 1038). 
Si entendemos que el término ideología ha sido definido como el "Conjunto de ideas fundamentales que caracteriza el pensamiento de una persona, colectividad o época, de un movimiento cultural, religioso o político, etc" (DRAEs. v.) y si coincidimos con el teórico ruso Batjin, citado por Forgas, en que la palabra es el fenómeno ideológico por excelencia, un diccionario de lengua puede verse, entonces, como un compendio de lo ideológico. Para esta autora, además:

Cada palabra - cada entrada de un diccionario-es, en realidad, un "ideologema", puesto que es a través de la definición lexicográfica que esa palabra se traslada a términos de sentido, o, lo que es lo mismo, a términos de ideología (1996: 73)

En esta aproximación al estudio del componente ideológico en los diccionarios cubanos hasta la década del 60 del siglo $\mathrm{XX}^{4}$, fruto de la creación individual de algunos aficionados y de algún especialista, se intentará develar los rasgos identitarios y culturales, expresados fundamentalmente en las opiniones de los diccionaristas acerca de:

- los diversos tipos sociales, las costumbres y otros rasgos nacionales,

— los componentes raciales,

- la sexualidad y la moral,

- la flora y la fauna,

- los platos de la cocina tradicional,

- la religión,

— los géneros musicales y danzarios,

— la historia nacional

4 Se ha tomado como límite a nuestra investigación esta década porque desde entonces se produjo un viraje en los estudios lingüísticos en Cuba, con la creación de institutos de investigación y la formación académica de muchos especialistas en las universidades cubanas y en los países del antiguo campo socialista. La lexicografía en particular no arribaría a su mayoría de edad hasta la incorporación de un equipo de investigadoras del Instituto de Literatura y Lingüistica a fines de la década del ochenta al Proyecto del Nuevo Diccionario de Americanismos de la Universidad de Augsburgo, oportunidad que no sólo transformó la práctica lexicográfica al uso y su dimensión teórica, sino que produjo una obra de equipo y no de autor, como había ocurrido hasta la fecha y desde los orígenes. 
- y los comentarios filológicos en torno a los rasgos que distinguen nuestra variante idiomática.

Nuestro acercamiento rozará, sin duda, la especulación, al intentar hurgar en nuestra historia nacional, en nuestra cultura y en nuestras raíces idiomáticas, a través de la mirada singular de los lexicógrafos, esos pacientes hacedores de diccionarios que por amor a las palabras se acercaron a ellas "sin dejarla(s) en paz hasta vencerla(s)". (Seco 2003). Desde el incansable geógrafo hasta el abogado en su gabinete, sin dejar al lingüista de formación, al etnólogo y a otros amantes de las palabras.

La investigación que proponemos tomará como muestra cinco piezas claves de la lexicografía nacional:

- el Diccionario provincial casi razonado de vozes y frases cubanas, de Esteban Pichardo y Tapia, de 1976 [1875];

- el Vocabulario cubano, de Constantino Suárez "El Españolito", en su edición de 1921;

- el Léxico cubano, de Juan Miguel Dihigo, en su edición de 1920, correspondiente a la letra A, y de 1945, correspondiente a la letra B;

- el Léxico Mayor de Cuba, de Esteban Rodríguez Herrera, publicado entre 1958 y 1959 ;

- y el Nuevo catauro de cubanismos, de Fernando Ortiz. La edición consultada es de 1985, pero su autor concluyó el Catauro en 1963, según apuntan los editores (1985: 7).

La selección de estos repertorios obedece fundamentalmente a la singularidad de la obra en su período histórico concreto y a la condición de sus creadores, su origen y su formación.

Una aproximación como la propuesta debe partir de los orígenes, por lo que el primer diccionario diferencial del español de América, fruto del esfuerzo del geógrafo Esteban Pichardo, debe ser tenido en cuenta. El repertorio tuvo cuatro ediciones: 1836, 1849, 1861-1862 y 1875 . En cada una el autor introdujo nuevos elementos conceptuales expresados en los títulos correspondientes: Diccionario provincial de voces cubanas, Diccionario provincial casi razonado de voces cubanas, Diccionario provincial casi razonado de vozes cubanas y Diccionario provincial de vozes y frases cubanas. La obra de Pichardo se inscribe, también, en 
la corriente lexicográfica que en una postura francamente vergonzante censuró las voces americanas y las calificó de idiotismos, vicios del lenguaje o corruptelas, como las llamara el propio Pichardo, quien en el entramado lexicográfico las separó a manera de suplemento. No puede ignorarse, por otra parte, su peculiar e ideológicamente condicionado tratamiento de las voces de origen africano, que aparecen sin marca ni advertencia alguna, frente a las entradas de los indigenismos que sí aparecen marcados.

Algunos ejemplos de la valoración subjetiva en torno al ingrediente negro de nuestro ajiaco nacional son:

Cabildo [...] Reunion de Negros y Negras bozales en casas destinadas al efecto los días festivos, en que tocan sus atabales y tambores y demás instrumentos nacionales, cantan y bailan en confusion y desorden con un ruido infernal y eterno, sin intermisión. Reunen fondos y forman una sociedad de pura diversion y socorro [...] (1976: 114).

Carretilla [...] Vehículo manuable de una sola rueda delantera y dos largueros para ambos manos del Negro que la dirige, asegurándolas además con los dos cabos de la correa que se echa por los hombros (1976: 149) .

Carabalí. El negro o negra de esta gran región de África. [...]. Aunque de carácter soberbio e indómito son trabajadores. (1976: 140).

Tango. Reunion de Negros Bozales para bailar al son de sus tambores y otros instrumentos. En Cuba se conoce por Tumba [...] (1976: 570).

El empleo aquí del pronombre posesivo se convierte en un marcador a nivel extratextual, en tanto nos permite advertir el distanciamiento cultural y social que el lexicógrafo delimita entre el universo de creencias y tradiciones culturales de los africanos traídos a Cuba y el hombre blanco, culto y civilizado.

Temas aparentemente ajenos a la subjetividad del lexicógrafo, tales como la descripción de la flora y la fauna, revelan también comentarios singulares en torno a las propiedades medicinales de una gran parte de

5 En todos los casos el subrayado es de la autora. 
las plantas registradas, como confirman las descripciones de los siguientes fitónimos:

Artemisa. Cr.-N. S.f.- Planta silvestre y comun: el tallo estriado se eleva a cuatro o cinco piés; las hojas de 5 pulgadas contienen varias divisiones u hojuelas verdes por encima y por debajo claro azulosas: hácia el estremo del tallo las flores en espigas, verdes, amarillosas, vueltas a la tierra. Es odorífera, amarga y excelente resolutivo en cataplasma (1976: 62).

Algarrobo criollo. Cub.- Arbol afín al algarrobo que se desarrolla silvestre, especialmente en la región oriental, hasta considerable altura, de buen follaje [...]. Exuda una especie de resina empleada en barnices y contra las afecciones pulmonares [...] (1976: 19).

La condición de extranjero de Constantino Suárez, quien era de origen español, decidió la inclusión del Vocabulario cubano en nuestro estudio, con el propósito de descubrir si dicha condición había permeado su obra o si no ocurrió tal cosa. Su aportación como diccionarista es apenas conocida en Cuba, así también los propósitos que inspiraron su obra. Suárez, quien también fuera novelista y periodista, concibió su Vocabulario como un suplemento a la decimocuarta edición del diccionario de la Real Academia de la Lengua y en el prólogo refiere sus experiencias en la labor, "de cuyas asperezas sólo tendrán noticia los que hayan compuesto o intentado componer un catálogo cualquiera de voces" (1921: IX).

La presencia del componente ideológico es abundante; podría anticiparse incluso que es uno de los autores menos "objetivos" en la construcción de sus enunciados definidores. Por ejemplo, en torno a novedades que se fueron produciendo en el ámbito musical, la reacción no se hizo esperar:

Danzón. Cub. m. - La pieza musical predilecta en todos los bailes, así del pueblo como de los salones aristocráticos, por lo que merece llamarse baile nacional. Su música no es delicada, pero sí voluptuosa y de cadencias un tanto incitantes. Entra en su composición, las muchas veces que la música no pertenece al autor, lo mismo un selecto trozo de ópera que cualquiera tonadilla callejera, predominando un cierto gusto de la música africana llamada rumba. [...] (1921: 189). 
son. Cub. $m$. Baile de origen africano y maneras indecentes, que usan los negros y la gentualla blanca. Toma ese nombre porque su música es un ruido sordo, seco y monótono de tambor. [...] (1921: 480).

Resultan de notable interés, por otra parte, los comentarios filológicos en torno a la presencia de anglicismos, un asunto que le provoca verdadera irritación, como se comprueba en este comentario suyo sobre algunos anglicismos aparecido en el prólogo: “ [...] aquel otro no menos repulsivo de mitin para lápida sepulcral de asamblea, sesión, reunión, congreso, conciliábulo, y hasta junta, que seguramente morirá también" (1921: XVI) o en la propia definición de interviú:

Interviú. Común. f.- Parece mentira que haya tomado tan hondas raíces este anglicismo innecesario en nuestro idioma, cuando podríamos substituirlo, según los casos, con una buena mozada de voces castizas entre las que sobresalen "entrevista", "visita", "consulta" [...]. Y es de advertir que muchos, por dárselas de que conocen el inglés, o para que se vea que lo saben, escriben interview, como si hubieran nacido en la misma Inglaterra (1921: 292).

En torno a la cultura y las tradiciones africanas se muestra muy crítico, como ocurre con los casos siguientes, en los cuales los prejuicios raciales y, en definitiva, culturales, se acentúan a través de adjetivos valorativos, expresiones hiperbólicas y del uso del pronombre posesivo "sus":

Andullo. Cub. m. Además del "andullo" que reseña la R.A., se conoce en la Isla una pasta de tabaco, negruzca y de repugnante olor, que muchos negros mastican con incomprensible deleite (1921: 26).

Bongó. Cub. $m$. Tambor que usan los negros en sus fiestas, y en el que producen una música tan desagradable, por lo sumamente monótona que no se explica sea entre ellos predilecta, la llaman son (1921: 72).

También encontramos numerosos enunciados definitorios que esconden cierta dosis de mojigatería o intención eufemística, como ocurre con la entrada siguiente:

Fletear. Excursión callejera de algunas prostitutas que buscan compañero (1921: 226). 
Así también alaba la belleza y cualidades de las plantas ornamentales, en un ilustrativo ejemplo de la presencia de subjetivemas o enunciados valorativos, "que se dan especialmente cuando el enunciador se reconoce implícitamente como la fuente evaluativa de la afirmación" (Forgas 2003: 12).

Almendro. Arbol silvestre que tiene la cáscara interiormente roja, la
madera blanca y el corazón almagrado; las hojas de dos a tres pulga-
das de largo, oblongas, aguzadas por ambos extremos, por cuya agra-
dable y peregrina apariencia se destina para alamedas y jardines
(1921: 49).

Imprescindible resulta la obra del único lingüista de esta hornada de lexicógrafos aficionados; se trata de Juan Miguel Dihigo. Al decir del estudioso cubano Rafael Martínez “ [...] además de ser el mejor de nuestros lingüistas, era al mismo tiempo el único" (1985: 58). Este reconocido filólogo dio entrada en su Léxico cubano a formas vulgares y populares de la modalidad cubana del español, con los correspondientes cambios morfológicos y semánticos y las explicaciones de los mismos a través de los principios fonéticos (Martínez 1985: 105). El Léxico consta de dos volúmenes que abarcan las letras A y B; el resto de las papeletas acopiadas por Dihigo no llegaron a publicarse, debido a la muerte del también miembro de la Academia Cubana de la Lengua. Al decir de Martínez (1985: 113, n 65), se trataba de un material que requería para su publicación de un intenso trabajo de revisión, cotejo y redacción, labor emprendida por Ernesto Dihigo y López-Trigo desde hace más de dos décadas.

De especial interés resulta, entonces, el abordaje de su obra y la identificación de rasgos de subjetividad en una obra de especialista, en la medida que puede aportar rasgos diferenciadores en comparación con el resto de los autores en estudio. Son reveladoras, en este sentido, las palabras del filólogo Julio Cejador y Frauca que sirven de prólogo al repertorio:

No dogmatiza, no insulta, no se enfurruña el Doctor Dihigo, no rebaja a los autores consultados para engreirse y entronizarse sobre ruinas y faltas ajenas, como otros hacen. [...]. Su estilo didáctico, claro, expresivo, natural, sin desplantes ni afectaciones, es el estilo del sabio (1920: VIII). 
En una rápida ojeada a las páginas del Léxico encontramos escasos ejemplos del fenómeno en estudio. De cualquier manera se debe profundizar mucho más, sobre todo en torno a los abundantes y enjundiosos comentarios filológicos que aparecen junto a definiciones y ejemplos que sirven para ilustrar el uso. La condición de especialista distingue toda la obra, que a pesar de haber quedado inconclusa, resulta esencial en la tradición lexicográfica cubana. El rastreo lexicográfico de innumerables diccionarios hispanoamericanos y en particular cubanos constituye, asimismo, otro de sus méritos indiscutibles.

Agüé. Forma adverbial que lleva en sí la característica del habla vulgar en boca de la clase de color. [...] (1920: 92).

Abolicionista. Usada para indicar la persona partidaria de la abolición de la esclavitud de los negros. [...]. Es curioso advertir cómo un término tan en consonancia con el sentimiento de los latinoamericanos no aparece en los léxicos que se han escrito (1920: 12).

Albur de arranque. Con esta expresión se indica el último albur en que, como dice Ortiz en Un Catauro de cubanismos, se juega el todo por el todo. Este aspecto semántico se aplica con frecuencia a los gobernantes que en una manifiesta desvergüenza y por hallarse al finalizar su término han dispuesto del tesoro de la nación. [...] (1920: 141).

Un estudio de frecuencia nos llevará a distinguir entre aquellos apuntes del propio Dihigo y aquellos que de alguna manera ya se adelantan en los diccionaristas citados, en cuyo caso el lingüista tiende a refrendar la definición, como en este último ejemplo.

En el caso de Rodríguez Herrera nos acercaremos al Léxico Mayor de Cuba, considerado por muchos "como el trabajo de mayor envergadura" (Alpízar 1989: 156) de este autor, filólogo y abogado de profesión y a quien también debemos otro repertorio fundamental, la obra Sinónimos jurídicos (1942), un aporte en materia jurídica.

En un detallado artículo sobre la presencia del componente ideológico en esta obra reunimos abundantes ejemplos que intentaron develar la huella del hombre en su creación (Camacho en prensa). Entre otros temas sobresalen sus opiniones en torno al tema femenino y a la moralidad de la época: 
Canela. s.f. Fig. se aplica a la mujer de raza mezclada, comúnmente mulata, cuando es de color claro, acercándose al bello tono de la canela, una de las especies más ricas por su delicado sabor y suave perfume, entre sus altas virtudes. Es vocablo familiar en Cuba, de uso festivo, con el cual se alude siempre a la mujer joven y bella descendiente de las dos principales razas del país, pero aventajando a una y otra en muchos de sus encantos físicos, celebrados por todos en todos los tiempos (1958, I: 273).

Pasada (estar). Expresión vulgar y fest. con que se da a entender que una mujer, por sus encantos y belleza, está extraordinariamente buena, en sazón para matrimonio, al extremo que está perdiendo tiempo si no lo aprovecha, o pasándose, en una palabra, como el plátano maduro para sinsonte, tan propio para comer (1958, II: 347).

Ahuevado. s.m. Manera indecorosa muy especial que emplean algunos bailadores, haciendo contorsiones lúbricas para provocar a la mujer. Puede practicar un hombre el ahuevado en el danzón, la rumba y hasta bailando sólo, por diversión, pero siempre resulta espectáculo amoral por deshonesto (1958, I: 52).

Así como sobre otras esferas de la vida nacional, costumbres y psicología social del cubano:

Cogioca (De coger), s.f.- Manejo de dinero, aunque no muy lícito ni cristiano (1958, I: 353).

Basurita s.f.- Cuba - Basurita decimos en Cuba a una cantidad mínima de dinero que se da o se pide por algún motivo, a una suma pequeñísima o insignificante de dinero. Una propina, si es generosa, merece ser aceptada; pero si es muy pequeña la dádiva se convierte en ... basurita. [...] Basurita no es regalo ni propina, sino mezquindad en forma de dinero. A veces se rechaza con soberbia y se le llama entonces, despectivamente, basura [...] (1958, I: 170).

Por otro lado, en su repertorio también ofrece información más cercana al diccionario enciclopédico o al recetario de cocina propiamente ${ }^{6}$, como ocurre con el la entrada siguiente:

6 Al respecto ya había reparado en mis apuntes sobre el vocabulario de la alimentación y su reflejo en los diccionarios cubanos (Camacho 1994: 11). 
Bienmesabe, s.m. Dulce compuesto de azúcar, almendras, harina de trigo, huevo, etc., [...]. En un libro español impreso en Madrid (1913) encontramos una fórmula para preparar el bien me sabe, pero a la manera americana y no española, pues dice: $\underline{\text { Se rallan, después de raspa- }}$ da, la cáscara oscura, dos cocos frescos, se exprimen mucho entre un paño, y toda la leche que suelten los cocos se ponen en el perol con mucha azúcar y cuando ha hervido se le agregan seis yemas de huevo [...] (1958, I: 187).

Acerca de la presencia de informaciones de esta naturaleza aparecidos en diversas ediciones del diccionario académico, la estudiosa María Ángeles Calero ha advertido en relación con el diccionario académico -y también puede señalarse con respecto a otra clase de diccionarios, añadimos nosotros- que "[...]debiera(n) ser el baúl léxico de una lengua, no el lugar donde los lexicógrafos opinen sobre lo divino y lo humano" (1999: 167).

El singular legado lexicográfico del etnólogo Fernando Ortiz, en particular su Catauro, es otra pieza clave de nuestro estudio. De tal manera se recrea en sus comentarios y disquisiciones sobre los diversos vocablos cubanos que el lector sensible puede palpar el genio creador del hombre común de esta tierra. Sus "cubicherías" matizan de fino humor toda la obra y dicho tono se origina en un conocimiento profundo y auténtico del hecho etnográfico y de la problemática del lenguaje en sí misma (Camacho 2000: 275). Encontramos, también, interesantes observaciones acerca de la historia nacional, de sus componentes y el papel que jugaron en la formación de la nación, del entramado sociorreligioso que nos distingue, de la política y sus vericuetos

Por ejemplo, en torno a ciertas costumbres Ortiz deja escuchar su vOZ:

Amarrar. Se denomina así al hecho ejecutado por un brujo o curandero cualquiera, para evitar la fuga o abandono de un ser por quien se siente afecto, o conviene tener bajo su voluntad.

La confección y venta de estos hechizos amorosos proporciona beneficios pecuniarios a los brujos. Las mujeres acuden con frecuencia al brujo para conseguir amarrar al marido o al hombre de sus anhelos. [...] 
O cuando opina acerca de la situación política en el país:
Albur. La expresión albur de arranque, significa el último albur, en que suele jugarse el todo por el todo. Se ha dicho reiteradas veces de los gobernantes, que próximos a cesar la presidencia u otros cargos, han realizado vergonzosos y desvergonzados apoderamientos de fon- dos públicos. "El general está en su albur de arranque" (1985: 41).
Cogedero. Cargo o puesto público donde es fácil y hasta usual (ipo- bre Cuba!) coger. "Ese puesto de lotería es un gran cogedero" (1985: 149).

Y en algunos casos al dejar brotar sus impresiones excluye la definición misma:

Partidarista. ¡Cómo nos llenamos la boca los políticos al achacar al adversario sectarismos partidaristas!. Y no pensamos que esta palabreja es un cultismo innecesario, teniendo ya el lenguaje a partidario y siendo preferible partidista. La abundancia de los istas en el campo político nos lleva hasta a deformar el lenguaje. Y si no fuera más que en el lenguaje ... (1985: 394).

En torno al tema negro, el pensamiento antropológico de Ortiz para la fecha en que comienza a trabajar en la primera versión del Catauro, ha comenzado a renovarse y su visión de la aportación africana a nuestro entramado nacional era ya respetada. No puede asombrarnos, sin embargo, que sus comentarios todavía revelen un incompleta comprensión del fenómeno unidas a un sincero respeto al definir aquellas voces esencialmente relacionadas con la presencia africana en Cuba. Reveladores de sus contradicciones son los siguientes ejemplos:

bilongo. Hechizo. [...] El hechicero afrocubano concentra generalmente el poder del hechizo en algo material; las prácticas de hechicería consistentes simplemente en maleficios o exorcismos por oraciones, bendiciones, conjuros, etc., revelan un grado superior de cultura religiosa, que no habían alcanzado la mayor parte de los hechiceros africanos (1985: 76).

bocabajo. Nombre que se daba a la pena de flagelación que sufrían los negros esclavos. Proviene este nombre de la posición que se hacía adoptar a la víctima, tendida en el suelo, dejando descubierto el dorso a la acción del foete. 
El bocabajo llevando cuenta era aquel que se imponía al negro agravándolo con la obligación de ir contando los latigazos que recibía, un error significaba recomenzar la pena que, por ser tal error cosa harto explicable y natural, se convertía en una flagelación sin duración realmente predeterminada que dependía del arbitrio del mayoral o de los contramayorales azotadores (1985: 78).

cáscara de vaca. Látigo de corto mango al cual se unía una tralla hecha comúnmente con finas tiras de cuero, que servía para flagelar a los esclavos. Era símbolo de autoridad en las plantaciones. La cáscara de vaca arrancaba en tiras el pellejo del esclavo, marcándolo con $\underline{\text { listas de sangre, que luego perduraban como verdugones y cicatrices }}$ (1985: 131).

Con estos pocos ejemplos, tomados al azar entre otros posibles e igualmente ilustrativos, nos acercamos al conocimiento y análisis del discurso lexicográfico cubano. Un estudio de esta naturaleza nos conducirá por un sendero fascinante: descubrir tras la palabra la emoción, el aplauso o la censura, el compromiso o el abandono; toda una gama de sentimientos y vivencias. Para Casares, un precursor:

No deja de tener atractivo este tipo de lexicografía, entendida como visión panorámica del léxico al través de un temperamento - por eso es obra de arte- y que si bien no permite saber el significado y la estimación colectiva de las palabras tal como se presentan al promedio de los hablantes en un momento determinado, nos procura, en cambio, el conocimiento entrañable de la psicología del lexicógrafo (1950: 162).

A nuestro juicio, la voz de un lexicógrafo revela mucho más que un temperamento individual y sí toda una gama de interpretaciones sociológicas y culturales de una época, una identidad y un imaginario social, en tanto el hombre se refleja en ellas.

Cabe preguntarse, una vez que nos adentramos en este estudio, si la subjetividad debe evitarse o no en los diccionarios y si esta presencia o ausencia podría vincularse con la tipología del diccionario; si su aparición más o menos explícita aporta elementos de interés ante la mirada del especialista o la del usuario común; y si aporta elementos de interés, cuál sería el rango permisible o aceptable de los ingredientes anímicos, subjetivos e ideológicamente condicionados; o si definitivamente suge- 
rencias y valoraciones como las aquí comentadas deben erradicarse del todo, en tanto un repertorio de palabras concentra un discurso científico que debe buscar la precisión y la objetividad.

Otro aspecto del fenómeno está relacionado con las marcas sociolingüísticas, de valoración social y de estratificación cultural y en tal sentido puede verse la presencia de lo subjetivo en dos dimensiones: una, como una prolongación de tales marcas y otra como un componente sustitutivo. Las inquietudes son numerosas y los caminos de análisis han sido escasamente abordados por la metalexicografía. Los diccionarios tienen mucho que decirnos, todavía.

\section{BIBLIOGRAFÍA}

AlpízAR, R. (s.f.): "La lexicografía en Cuba, hoy", documento mecanuscrito, $12 \mathrm{p}$.

Alpízar, R. (1989): Apuntes para la historia de la lingüística en Cuba, La Habana, Ed. Ciencias Sociales.

Alvar Ezquerra, M. (1993): "Diccionario y política", en Lexicografía descriptiva, Barcelona, Biblograf, pp. 181-191.

AngladA, E. y M. BARGALló (1992): "Principios de lexicografía moderna en los diccionarios del siglo XIX", en Actas del II Congreso Internacional de Historia de la Lengua Española, Madrid, Arco/Libros, pp. 955-962.

CALERo, Ma A. (1999): "Diccionario, pensamiento colectivo e ideología (o los peligros de definir)", en Así son los diccionarios, Lleida, Universitat de Lleida, pp. 149-201.

CAmacho, A. (1994): Del español de Cuba: apuntes lexicológicos, La Habana, Editorial Científico-Técnica.

Camacho, A. (2000): "Fernando Ortiz, lexicógrafo", Montalbán, 33, pp. 269-278.

CAmacho, A. (en prensa): "Diccionario e ideología: el Léxico Mayor de Cuba, de Esteban Rodríguez Herrera", en Volumen monográfico dedicado a la lexicografía en Cuba, Universidad de Valencia.

CASARES, J. (1950): Introducción a la lexicografía moderna, Madrid, Consejo Superior de Investigaciones Científicas.

Forgas, E. (1999): "Lengua, sociedad y diccionario: la ideología”, en E. Forgas (coord.), Léxico y diccionario, Tarragona, Universitat Rovira i Virgili, pp. 71-89. 
Forgas, E. y M. Herrera (2000): "Diccionario y discurso: la emergencia de los fenómenos enunciativos", en J. J. de Bustos et al. (eds.), Lengua, discurso, texto, Madrid, Visor, pp. 1035-1048.

Forgas, E. (2003): Convocatoria de ayudas de Proyectos de Investigación (2004). Memoria científico-técnica del proyecto "Análisis y evaluación del lenguaje lexicográfico: la subjetividad lingüistica en el texto del diccionario", Tarragona, Universidad Rovira i Virgili. Documento electrónico.

LARA, L. F. (1990): Dimensiones de la lexicografía. A propósito del Diccionario del español de México, México, El Colegio de México.

Martínez, R. (1985): Juan Miguel Dihigo: gran lingüista cubano, La Habana, Editorial Letras Cubanas.

PÉrez, F. J. (2000): Diccionarios, discursos etnográficos, universos léxicos, Caracas, Universidad Católica Andrés Bello.

SECO, M. (1987): “Ramón Joaquín Domínguez", en Estudios de lexicografía española, Madrid, Paraninfo, pp. 154-164.

SECo, M. (2003): "Los lexicógrafos", Conferencia inaugural del II Curso de Especialización en Lexicografía Hispánica de la Real Academia Española, material impreso.

\section{DICCIONARIOS}

Dinigo, J. M. (1920): Léxico cubano. Contribución al estudio de las voces que lo forman, La Habana, Imprenta "El Siglo XX" (volumen I), Editorial Selecta (volumen II, 1945).

Ortiz, F. (1985): Nuevo catauro de cubanismos, La Habana, Editorial de Ciencias Sociales.

PICHARDO, E. (1976): Diccionario provincial casi razonado de vozes y frases cubanas, La Habana, Editorial de Ciencias Sociales.

Real Academia de la Lengua (200122): Diccionario de la Lengua Española, Madrid, Espasa Calpe.

Rodríguez Herrera, E. (1958-1959): Léxico Mayor de Cuba, tomos I y II, La Habana, Editorial Lex.

SuÁREZ, C. (El Españolito) (1921): Vocabulario cubano, Suplemento a la 14 edición del Diccionario de la R.A. de la Lengua, Madrid-La Habana, Librería Cervantes de Ricardo Veloso-Librería de Perlado, Páez y Cía. 